\title{
Argumentatividad y polifonía en libros escolares. Un análisis microdiscursivo en libros de texto argentinos
}

\author{
Argumentatity and polyphony in textbooks. A micro-discursive \\ analysis in secondary school textbooks
}

\section{CAROLINA LUCIANA TOSI}

Universidad de Buenos Aires

Argentina

Resumen. Los libros de texto suelen ser el primer contacto que tienen los alumnos con los materiales de estudio y, por ende, se constituyen como el material de iniciación a las prácticas de la lectura disciplinar. Atento a ello y sobre la base de abordajes previos (Tosi, 2008, 2009, 2010a, 2010b y 2010c), en este trabajo analizamos ciertos modos de formulación lingüística de los libros escolares de nivel Secundario con el fin de averiguar en qué medida su configuración discursiva contribuye al aprestamiento de la lectura de textos especializados. Específicamente, abordamos los diferentes modos de referencia al discurso ajeno en un corpus de libros de texto editados en la Argentina a partir del advenimiento de la democracia (1983) hasta 2006. Finalmente, planteamos algunos de los alcances de las estrategias discursivas registradas.

Palabras clave: discurso pedagógico; lectura; libros de texto; explicación; citas.

\begin{abstract}
Textbooks are usually the first instance in which students get in contact with study tools and, therefore, they constitute the material for the initiation into the practice of reading disciplinary texts. Taking this idea into account and on the basis of previous approaches (Tosi, 2008, 2009, 2101a, $2010 \mathrm{~b}$ and 2010c), this article presents the analysis of certain ways of linguistic formulation in secondary school textbooks, aiming to find out to what extent their discursive configuration contributes to the process of initiation into reading specialized texts. Specifically, this article deals with the different ways of reference to referred discourses within a corpus of textbooks edited in Argentina from the advent of democracy (1983) until 2006. Finally, it sets out some of the scopes of the discursive strategies that have been registered.
\end{abstract}

Keywords: pedagogical discourse; reading; textbooks; explanation; quotations. 


\section{Introducción}

En las últimas décadas, se ha registrado un creciente interés desde distintas líneas de investigación por estudiar la relación entre discurso y comprensión lectora. Una de estas líneas, inscripta en la Teoría de la Enunciación, se ha ocupado de analizar los géneros académicos que comunican conocimiento y demostró que ciertos procedimientos microdiscursivos constituyen verdaderos puntos críticos de incomprensión (Hall y Marin, 2003a y 2003b, García Negroni, Marin y Hall, 2005 y 2006). Entre estos procedimientos, las investigadoras destacan las nominalizaciones, la sintaxis desagentivada, la sintaxis desligada y la acumulación de incisos, el desplazamiento del foco informativo por anteposición de concesiones de carácter refutativo o por la inclusión de negaciones metalingüísticas y negaciones litóticas ${ }^{1}$. Por nuestra parte, y dado que los libros de texto suelen ser el primer contacto que tienen los alumnos con los materiales de estudio y se constituyen como el material de iniciación en las prácticas de lectura disciplinar, hemos analizado (Tosi, 2008, 2009 y 2010a y 2010b) algunos de los procedimientos microdiscursivos que se erigen como obstáculos para la comprensión, como la sintaxis desagentivada, los comentarios metadiscursivos (Gülich, y Kotschi, 1995) y las formas de heterogeneidad mostrada marcada (Authier, 1984, 1995), entre otros.

En esta oportunidad, y atento a que las dificultades principales que manifiestan los estudiantes de los niveles superiores -y también del Secundario- residen en "reconocer las dimensiones argumentativas, la presentación de enfoques contrapuestos y en conflicto de distintos autores y explicitación del punto de vista del autor del texto" (García Negroni, Hall y Marín, 2005: 4), abordamos los aspectos relacionados con el

\footnotetext{
${ }^{1}$ Por un lado, se entiende por desagentivación al conjunto de procedimientos microdiscursivos propios del discurso científico que, en busca de la mayor objetividad posible, tratan de ocultar el sujeto en beneficio del objeto. Entre ellos se destacan la conversión de activa a pasiva, las nominalizaciones y la construcción impersonal con "se". (Hall y Marin, 2003a y 2003b y García Negroni, Marin y Hall, 2005 y 2006). En tanto que la sintaxis desligada, tal como la caracteriza Benveniste (2000), incluye procedimientos sintácticos tales como la inclusión de aposiciones y de construcciones absolutas. A estos mecanismos, (Hall y Marin, 2003a) han agregado los incisos parentéticos, los cuales acumulan información en un mismo enunciado. Por otro lado, el desplazamiento del foco informativo es un procedimiento en el nivel de la composición de los enunciados que, según las autoras, obedece a la ocultación de la argumentatividad en el discurso expositivo-explicativo. Se trata de un procedimiento muy habitual en la discursividad de las ciencias, que consiste en iniciar un enunciado, frecuentemente el que inicia un párrafo, con una cláusula concesiva o condicional que queda, entonces en posición temática (Hall y Marin, 2003a). Finalmente, las autoras indican que las negaciones litóticas son negaciones que equivalen a afirmaciones mitigadas (ejemplo: no está mal, no deja de+ infinitivo).
} 
carácter polifónico del libro de texto. El objetivo es averiguar en qué medida su configuración discursiva contribuye al aprestamiento en la comprensión de textos disciplinares, los cuales, como es sabido, presentan un alto grado de argumentatividad.

Cabe precisar que las categorías de dialogismo y polifonía proceden de los trabajos de M. Bajtín (1982), quien sostiene que todo discurso se inscribe en una interacción, más o menos explícita, con otros discursos que es diacrónica y sincrónica: el enunciado se encuentra siempre en relación con otros enunciados, a los que alude, confirma, rechaza o reelabora. En efecto, M. Bajtín postula que las palabras son siempre palabras de los otros y que todo discurso reformula voces ajenas. Por su parte, O. Ducrot (1984), en su formulación de una semántica argumentativa, retoma algunas de las premisas de Bajtín e incorpora la noción de polifonía como eje central para la descripción del sentido de las entidades de la lengua. El autor considera que el sentido de las entidades lingüísticas no está conformado por las cosas, los hechos o las propiedades que ellas denotan, ni por los pensamientos que las suscitan, sino por ciertos discursos que les están asociados.

El corpus de análisis se compone por libros de los primeros años del Secundario de diferentes disciplinas (Lengua y Literatura, Ciencias Sociales y Ciencias Naturales), publicados entre 1983 y 2006 por las editoriales de mayor difusión y venta en la Argentina $^{2}$. Es preciso tener en cuenta que en la Argentina, luego de la crisis de la industria editorial durante la dictadura militar (1976-1982), se instaló una nueva coyuntura político-económica, y se registraron cambios en la construcción discursiva tradicional de los manuales escolares, que se potenciaron y consolidaron en la década de 2000. En este sentido, la influencia del diseño gráfico, las nuevas corrientes pedagógicas, el desligamiento en la regulación de los materiales educativos por parte del Estado y la conformación de un mercado editorial competitivo -caracterizado por el ingreso de editoriales extranjeras, y la fusión y compras de las empresas argentinas por grupos multinacionales, entre otros aspectos- dieron lugar a nuevas propuestas editoriales con características discursivas específicas.

A continuación, damos cuenta de los aspectos discursivos de los libros de texto y estudiamos sus cambios. Luego, analizamos la dimensión polifónica y argumentativa de

\footnotetext{
${ }^{2}$ Los datos bibliográficos del corpus utilizado se encuentran al final del trabajo.
} 
los libros de nuestro corpus y nos centramos en abordar algunas de las formas de referencia al discurso ajeno, en especial, la inclusión de citas $^{3}$. Finalmente, planteamos algunos de los alcances de las estrategias discursivas registradas.

\section{El libro de texto y la ilusión de transparencia}

Como es sabido, el libro de texto expone saberes legitimados -producidos en las distintas esferas del ámbito académico- que se presentan recontextualizados en relación con la nueva situación comunicativa en la que se inscribe, las características genéricas y sus destinatarios directos e indirectos -los alumnos y los docentes-. En este sentido, tal como sostiene Bernstein [1975] (2005), el dispositivo pedagógico, es decir el "conjunto de reglas y prácticas para la formación y transformación de la comunicación pedagógica" (Bernstein, [1975] 2005: 139), se constituye a través de ciertos criterios de recontextualización mediante los cuales el texto de base es modificado por selección, simplificación, condensación y elaboración.

Uno de los mecanismos de recontextualización implementados tradicionalmente por el libro de texto para lograr que la explicación que se perciba como sencilla, clara y veraz lo constituye la anulación de la referencia explícita a las múltiples voces de textos anteriores (Hyland, 2000). A diferencia de los géneros científico-académicos que suelen caracterizarse como espacios de dialogismo (Hyland, 2000; Bolívar, 2005; García Negroni, 2008), pues sus autores se posicionan como miembros de la comunidad científica y suelen hacer referencia a investigaciones previas para acordar o disentir de ellas y así incorporar su propia contribución al acervo disciplinar, el libro de texto intenta mostrarse monódico. Al exponer un saber recontextualizado, producto de la transposición didáctica, el libro escolar suele borrar las huellas del enunciador del texto científico o normativo que reformula y ocultar los diferentes puntos de vista, para generar la "ilusión de la transparencia" (Chevallard, 1991) y construir un discurso en apariencia objetivo y neutro (Hyland, 2000, Orlandi, 2009 y Tosi, 2010 b y 2010c).

No obstante, existe un cierto consenso actual al valorar y considerar a los libros editados recientemente como abiertos y permeables a la incorporación de múltiples

\footnotetext{
${ }^{3}$ Para consultar sobre un análisis de otras formas de heterogeneidad mostrada marcada en los libros de texto, como el uso de comillas y tipografía especial, véase Tosi (2008 y 2010a).
} 
voces, en contraposición a los de la generación anterior que suelen ser caracterizados como monódicos (Romero, 2004) ${ }^{4}$ Al respecto, señalamos que efectivamente durante las últimas décadas diversos factores -como los nuevos enfoques pedagógicos propuestos por la Reforma Educativa, cuyo principal referente es la Ley Federal de Educación (1993), y las tendencias del diseño editorial por desplegar formatos novedosos- propiciaron ciertas innovaciones, como la incorporación de discursos ajenos disciplinares y no disciplinares en recuadros paratextuales, que variaron la construcción discursiva de los libros escolares. Ahora bien, ¿estas transformaciones realmente cambiaron la pretensión de constitución de un discurso monódico? ¿Introdujeron perspectivas que contribuyen a la manifestación de la diversidad de posturas y la confrontación entre puntos de vista? ¿Esta inclusión de "multiplicidad” de voces configura textos explicativos que exponen la presencia de perspectivas diferentes? Finalmente, dado que los libros de texto suelen ser el primer contacto que tienen los alumnos con los materiales de estudio, nos preguntamos si su nueva configuración discursiva contribuye al aprestamiento en la comprensión de textos especializados. Para obtener respuestas ante estos interrogantes, analizamos a continuación ciertos mecanismos microdiscursivos utilizados para referir al discurso disciplinar, y luego reflexionamos sobre sus alcances y posibles efectos de sentido.

\section{Los modos de referir el discurso ajeno en los libros de texto de la democracia}

Sobre la base de la nueva plataforma sociopolítica que se inicia hacia 1983 y promulga valores democráticos y pluralistas, emerge y se evidencia en los planes editoriales de la época la necesidad imperiosa de modificar el tratamiento temático de los libros de texto. Así, desde diferentes sectores de la sociedad argentina -los espacios académicos universitarios, las nuevas corrientes pedagógicas, los ámbitos de legislación educativa y también de la opinión pública en general-, surgió paulatinamente el planteo de que los

\footnotetext{
${ }^{4}$ Los libros editados en la Argentina previamente a la democracia (1983) suelen ser caracterizados por los especialistas como relatos únicos, cerrados y autoritarios. En relación con los libros de Historia, Romero comenta: "Mientras estos [los autores] criticaban el relato único, cerrado y autoritario, el diseño gráfico reducía el lugar del texto principal y llenaba las páginas con elementos complementarios y distractores. A través de esos elementos, se incorporaban al relato principal otras voces, pero con tal fuerza que la principal, reducida a su mínima expresión, se perdía en el conjunto. En suma, por la acción concurrente de los autores y sus editores, los libros de texto dejaron de ofrecer una versión, un relato de la geografía o de la historia" (Romero, 2004: 221).
} 
libros escolares debían exhibir diversas voces y no cerrarse en una exposición hegemónica. Las editoriales, poco a poco, fueron captando este pedido y, desde entonces, sus propuestas pretendieron colmar tales expectativas. Si bien, a través del despliegue de ciertos mecanismos lingüísticos que analizaremos a continuación, los libros de texto incorporaron discursos ajenos en sus páginas, consideramos que la explicación de los temas se mantuvo con pretensiones de mostrarse monódica, pues no suelen incluirse referencias explícitas a autores académicos o discursos disciplinares previos. Por ende, el resultado es la ilusión de una explicación construida desde la multiplicidad manifiesta de voces y diferentes puntos de vista, cuando en realidad el saber transmitido en los segmentos expositivos se sigue configurando con pretensiones de neutralidad y transparencia.

Para lograr tal puesta en escena discursiva, las propuestas editoriales suelen configurar dos espacios textuales, en cada uno de los cuales despliegan diferentes mecanismos de reformulación y de referencia a la voz ajena. Una de esas zonas discursivas se encuentra conformada por los segmentos explicativos -la teoría-, donde la voz divulgada tiende a desdibujarse y ocultarse. Por el contrario, ciertos elementos subsidiarios a la explicación central -ubicados en zonas paratextuales, páginas especiales o secciones especiales-, se erigen como espacios de alteridad explícita que manifiestan una mayor cantidad de citas, pero que no siempre se relacionan con la voz divulgada expuesta en los segmentos explicativos.

\subsection{La voz del saber: la reformulación pedagógica en los segmentos} explicativos

En los manuales de las últimas décadas, diversos elementos verbales, icónicos y materiales han confluido en su configuración. Esta tendencia se percibe en los manuales publicados en muchos países, como sucede en Argentina y también en el caso español, según lo comentan Somoza Rodríguez y Ossenbach Sauter (2004):

Los elementos iconográficos fueron ocupando ("invadiendo") el espacio del manual escolar, tanto en cantidad de ilustraciones como en tamaño de las mismas, no siempre aportando información relevante respecto de los contenidos. En múltiples casos lo meramente decorativo comenzó a predominar por sí mismo, buscando atraer por la calidad de las imágenes y el colorido la atención de un 
público escolar (y de sus padres) interpelado más como consumidor de un objeto comercial atractivo que como sujeto de aprendizajes sociales valiosos. (p. 3)

A pesar de esto, la puesta en escena discursiva brinda una serie elementos que le permiten al lector jerarquizar sus componentes. Por ejemplo, el espacio dado a los segmentos explicativos en cuanto a la extensión y al lugar que ocupa en la página -suele estar en la columna central-, muestra que allí se encuentra el saber legitimado, aquel que el alumno reconoce como "la teoría" y es el que debe estudiar y aprender para aprobar la materia.

Debido a que el libro de texto es un género que se caracteriza por su pretensión de modelar certezas, en la sección teórica se construye discursivamente un conocimiento "legítimo", "en procura del efecto de objetividad que surge del hablar en nombre de la ciencia" (Zamudio y Atorresi, 2000: 128). En este sentido, y en tanto discurso de reformulación didáctica, el libro de texto emplea estrategias de simplificación lingüística, como no incluir discursos referidos ni hacer mención explícita a los autores o teorías que se exponen. Así, la voz divulgada tiende a encubrirse.

De acuerdo con análisis previos (Tosi, 2010b y 2010c), los conceptos se presentan bajo la forma de "resultados" sin incluir la fuente de enunciación responsable ni la tradición teórica que propuso o acuñó la terminología en cuestión. A modo de ejemplo, presentamos las secuencias explicativas en donde se desarrollan las nociones de "esquema de comunicación" (1), "macromoléculas" (2), las consecuencias de la Conquista para los “amerindios" (3) y la "vacilación” del cuento fantástico (4).

(1) En toda comunicación, alguien (el emisor) dice algo (el mensaje) a un destinatario (el receptor) acerca de un tema (el referente). El mensaje se construye mediante un sistema de signos (el código) se transmite a través de un medio (el canal), que puede ser, por ejemplo, una publicación escrita, el teléfono, el correo, en forma electrónica, cara a cara, etcétera. (Lengua y Literatura)

(2) Las moléculas biológicas son aquellas que están presentes en la constitución de los seres vivos. Como las moléculas biológicas están formadas por un gran número de átomos, tienen una masa molecular elevada; por este motivo se las denomina macromoléculas. (Ciencias Naturales)

(3) Para los amerindios, el impacto de la superior civilización europea fue mucho más fuerte aún. La conquista y la implantación de la civilización europea interrumpió 
totalmente el desarrollo de las civilizaciones precolombinas más avanzadas y los "indios" de todo el continente se vieron paulatinamente desplazados o sometidos por los europeos. En grandes regiones el indígena fue integrado a la vida colonial; otros permanecieron alejados de la civilización y en permanente guerra con ella hasta el siglo XIX; en algunos casos -en las Antillas- el aborigen fue totalmente extinguido. Sin embargo, el contacto de los dos mundos produjo a la larga... (Historia)

(4) El cuento fantástico tiende a la ambigüedad, porque permite que se lo pueda explicar de maneras diferentes. Esta ambigüedad cuestiona el carácter realista y verosímil de lo narrado. Frente a ella, el lector vacila entre dos interpretaciones. Por un lado, su experiencia de lo real y lo cotidiano lo motiva a encontrar una explicación lógica y natural de los sucesos narrados; por otro, la naturaleza ilógica de los hechos lo inclina hacia una explicación sobrenatural. (Lengua y Literatura) ${ }^{5}$

Como observamos, en ninguno de los casos se introducen referencias a los autores responsables de las nociones o teorías, y ni siquiera se tienen en cuenta las variaciones conceptuales o de paradigma que estas han tenido. Por ejemplo, no se indica que Roman Jackobson es el creador del "modelo de la comunicación” expuesto en (1) ni quién postuló la noción de "macromolécula" en (2). Respecto de (3), tampoco se explicita cuál es la fuente de la explicación de las consecuencias de la Conquista. Los hechos, entonces, se presentan como verdades, aunque la explicación se encuentre plagada de valoraciones e incluso de expresiones incorrectas y discriminatorias; por ejemplo, se menciona que la civilización europea era "superior" a la de los pueblos originarios, que el aborigen fue "extinguido" y que la Conquista se trató de un “encuentro entre dos mundos", etc. Por su parte, en (4), además de no explicitar de qué teoría se ha extraído el concepto de "vacilación", no hay ninguna referencia a las diferentes concepciones existentes respecto del cuento fantástico (como las de Tzvetan Todorov, Rosemary Jackson o Julio Cortázar, entre muchos otros).

A través de estos ejemplos observamos cómo se construye una versión didáctica de los conceptos, en pos de modelar una exposición llana y sencilla, sin conflictos epistemológicos (Tosi, 2010b y 2010c). Al silenciar las fuentes, al no incorporar explícitamente discursos previos, puntos de vista diferentes ni remitir a los enunciadores responsables, la explicación puede ser percibida por los destinatarios como "natural", "experiencial", "transparente" y no como lo que es: el resultado de polémicas disciplinares y de una compleja construcción teórica. Así, observamos cómo la fuente

\footnotetext{
${ }^{5}$ Los ejemplos se introducen con la tipografía original (redondas, negritas y bastardilla) y haciendo mención a la disciplina a la que corresponden.
} 
divulgada desaparece, la responsabilidad del autor del libro de texto también se desdibuja (mediante diferentes estrategias, como las de despersonalización) y el discurso pretende construirse como una "verdad" y no como una interpretación desde un punto de vista. En este sentido, los libros de texto recurren en sus secuencias explicativas al ocultamiento del carácter argumentativo y polifónico que, tal como sostienen Pereira y Di Stéfano (2001) y Marin y Hall (2003a), son elementos discursivos característicos de los textos que comunican conocimiento.

Si bien encontramos en los segmentos explicativos algunas referencias al discurso ajeno, la cantidad es muy escasa. Por ejemplo, cuando analizamos las secuencias explicativas de los libros de tres disciplinas editados por una misma editorial en un mismo año y dentro de la misma colección, obtuvimos estos datos:

- $\quad$ en Ciencias Sociales de 230 subtemas $^{6}$ solo 9 presentan referencias al discurso ajeno;

- $\quad$ en Ciencias Naturales de 181 subtemas, solo 26 presentan referencias al discurso ajeno; y

- $\quad$ en Lengua y Literatura no hay casos de referencia al discurso ajeno.

Cuadro 1. Cantidad y porcentajes de referencias a la fuente del discurso divulgado en libros de diferentes disciplinas de una misma editorial.

\begin{tabular}{|l|c|c|c|}
\hline Disciplinas & Subtemas totales & $\begin{array}{l}\text { Subtemas con referencias a } \\
\text { la fuente del discurso divulgado }\end{array}$ & $\begin{array}{c}\text { Porcentaje de referencias a la } \\
\text { fuente del discurso divulgado }\end{array}$ \\
\hline Ciencias Sociales & 230 & 9 & $4 \%$ \\
\hline Ciencias Naturales & 181 & 26 & $0 \%$ \\
\hline Lengua y Literatura & 200 & 0 & $15 \%$ \\
\hline
\end{tabular}

Sin duda, la cantidad de referencia a la fuente del discurso divulgado es muy baja y los porcentajes nunca superan el $15 \%$.

\footnotetext{
${ }^{6}$ Para llevar a cabo el abordaje, consideramos que cada página desarrolla un subtema

${ }^{7}$ Es de destacar que los segmentos explicativos Ciencias Naturales presentan una mayor ocurrencia de referencia a discurso ajeno, mientras que Lengua y Literatura es el área que menos referencias incluye. En relación con la ocurrencia de citas en las disciplinas, esta tendencia se repite en todas las propuestas
} 
3.2. La voz exhibida: la palabra ajena "re-construida" en las zonas paratextuales.

Mientras que las secuencias explicativas presentan el saber configurado como monódico y neutro - a partir de la escasa referencia al discurso ajeno, entre otros recursos-, las zonas paratextuales compuestas por recuadros u otros recursos gráficos, tales como viñetas o formatos de periódicos o entradas de enciclopedia, se erigen como espacios de alteridad discursiva. En efecto, las citas aparecen dentro de elementos paratextuales y se muestran como explícitamente ajenas y externas a la voz constituida en la explicación. Se puede tratar de textos académicos disciplinares o de discursos de otros géneros pertenecientes, por ejemplo, a la prensa en general, a la divulgación científica en particular, a materiales de consulta como enciclopedias y páginas-web, etcétera.

La inclusión de las referencias ajenas proviene, sin duda, de la necesidad de generar materiales escolares que presenten una atractiva variedad de discursos y exhiban un espíritu plural y "democrático", como ya mencionamos en $\S 2$. Los lineamientos de la Reforma Educativa de 1993 ratifican tal objetivo; por ejemplo, los Contenidos Básicos Comunes (CBC) recomiendan para Ciencias Sociales la inclusión de textos de distintas fuentes, especialmente de los medios de comunicación, y destacan como saber valioso:

El conocimiento de los diferentes tipos de materiales a través de los que se obtiene y procesa información acerca de la realidad social (material cartográfico, fuentes sobre el pasado, estadísticas y registros cuantitativos, textos e imágenes proporcionados por los medios de comunicación). Los mismos serán trabajados en relación tanto con el tipo de información que ofrecen como con los lenguajes y recursos expresivos que los distinguen (Ministerio de la Nación, CBC, 1995).

Por su parte, la normativa oficial promueve, respecto de las Ciencias Naturales, la formación de los alumnos en alfabetización científica como parte de una necesidad educativa global y por ello anima la consulta de materiales de divulgación científica:

En la actualidad hay enormes cantidades de personas que se podrían considerar científicamente ignorantes. Más allá de las diferencias en la apropiación de los beneficios sociales que traen aparejados los diversos desarrollos científicos que se expresan con sumo patetismo en el campo de la salud esta ignorancia se puede 
observar en las dificultades que se observan en muchas personas para comprender una noticia gráfica o televisiva de divulgación científica (Meinardi, 2005: 2).

En este sentido, poner en contacto a los alumnos con géneros o formatos propios de la divulgación de la ciencia apuntaría a la formación de lectores críticos de información científica, que puedan "analizar artículos periodísticos científicos" (Meinardi, 2005: 2). Si bien en las propuestas editoriales analizadas registramos la incorporación de discursos ajenos, estos provienen casi siempre de la divulgación científica. En muy pocos casos se trata textos académicos disciplinares como, por ejemplo, informes o artículos científicos, que consideramos podrían ser un buen punto de partida para iniciar a los alumnos en la lectura de ese tipo de discursos.

En consecuencia, sobre la base de las recomendaciones curriculares y de los nuevos enfoques didácticos que animan la introducción de perspectivas diversas, las propuestas editoriales han modificado las maquetas, es decir los diseños de página, respecto de los libros de la generación anterior y, comenzaron a contemplar espacios gráficos especiales para ubicar la voz ajena. En efecto, cuando los libros de nuestro corpus exhiben las voces ajenas lo hacen separándolas y diferenciándolas de la explicación central, que se sigue configurando como llana -sin "contaminación" de voces- y lo más clara posible se muestra una sola voz que explica el saber legítimo tal como hemos mostrado en el apartado anterior.

A través de la introducción del discurso ajeno en las zonas paratextuales el autor del libro de texto se posiciona como experto y conocedor de las propuestas metodológicas actuales en relación con sus destinatarios: da cuenta de que conoce y maneja no solo los conceptos del campo disciplinar, sino también información tomada de soportes variados. De este modo, los autores exhiben su experticia y conocimiento del estado de la disciplina, y ofrecen una imagen de sí experta e innovadora. Pero, además, la inclusión de fuentes y de diversos géneros ofrece una variedad discursiva novedosa y atractiva para los lectores -para alumnos aunque en mayor medida para los docentes-.

En relación a la funcionalidad de las referencias a discursos ajenos en espacios paratextuales consideramos que estas no son utilizadas como evidencia citativa $^{8}$

\footnotetext{
${ }^{8}$ En este punto, debemos referirnos al concepto de evidencialidad propuesto por Chafe (1986), que se relaciona con las actitudes del sujeto frente al conocimiento. Chafe señala cuatro modos de conocimiento,
} 
(Chafe, 1986), es decir a modo de refuerzo argumentativo del saber y aval de autoridad. $\mathrm{Al}$ respecto se debe tener en cuenta que el libro de texto no construye conocimientos como sí sucede en el discurso académico, donde los autores deben dar pruebas de la originalidad y novedad de sus aportes. Por el contrario, los libros de texto son depósitos de conocimiento codificado y consensuado, que muestran los paradigmas de cada disciplina (Hyland, 2000). Al reflejar el canon, exponen un saber legitimado que ningún miembro competente de la disciplina cuestionaría y, de este modo, comunican "verdades" ya probadas y por eso no necesitan señalar la fuente de donde se han obtenido. Mediante la puesta en escena discursiva, la explicación de los libros de texto muestra aseveraciones que se perciben como hechos ya establecidos y establecidos como verídicos. En este sentido, la inclusión de discursos ajenos en las zonas paratextuales no tiene el objetivo de mostrar evidencias de validez del saber expuesto, más allá de que la alusión a un teórico reconocido o a datos aportados por organismos prestigiosos, seguramente, pueda reforzar su legitimidad. Por el contrario, consideramos que la función primordial de la cita es servir como recurso de ejemplificación o ilustración, en pos de ciertos objetivos pedagógicos, como lograr que el alumno amplié un tema a partir de una postura teórica generalmente afín a la expuesta en la teoría. Por ejemplo, en (5) el recuadro incluye una cita integrada (Bolívar, 2005) que funciona como ilustración o ejemplo de la denuncia de un trabajador. Sin duda, las citas integradas que "no interrumpen el texto, pero que se colocan entre comillas o en cursivas y pasan a formar parte del discurso del autor" (Bolívar, 2005: 83), dejan claras las fronteras entre el discurso citado y citante.

En (6), la cita de parafraseo (Bolívar, 2005) es introducida por la preposición según y sirve para proporcionar un dato extra sobre la "fuga de cerebros", en la Argentina. A través de citas de parafraseo, que son "aquellas partes del texto que se refieren o mencionan las ideas, conceptos e investigaciones de otros autores y que se acompañan con el nombre del autor y/o número de página (opcional)" (Bolívar, 2005: 84), se proporciona evidencia sobre el saber de un otro reconocido, aunque no se consignan los datos de la fuente como sí lo exigiría la norma académica.

cuyas fuentes asignan más o menos confiabilidad: la creencia, la inducción, la información sensorial y la deducción. Particularmente, Chafe expone que en la evidencia sensorial el tipo de evidencia es perceptual. En este sentido, la escritura académica el conocimiento obtenido a través del lenguaje se indica con los recursos formales propios del discurso citado (citas) y constituye la evidencia sensorial 
Finalmente, en (7) aparece una cita destacada (Bolívar, 2005), en la que se reproducen ciertas ideas de Hipócrates. Se debe tener en cuenta que las citas destacadas son "aquellas citas textuales que, por su longitud, generalmente interrumpen el texto" (Bolívar, 2005: 83).

\section{(5) Las condiciones de trabajo}

Las condiciones de trabajo en las fábricas fueron estudiadas en informes encargados por comisiones parlamentarias, denunciadas por reformadores sociales y relatadas por los propios trabajadores en entrevistas y autobiografías. El siguiente fragmento forma parte de una declaración del obrero James Patterson ante un comité parlamentario británico en 1832: "Yo trabajaba en la fábrica del Sr. Braid en Duntruin. Trabajábamos todo el día mientras pudiéramos ver. No podría decir a qué hora parábamos. No había reloj en la fábrica. Solo el patrón y el hijo del patrón tenían reloj, así que no sabíamos la hora. No se permitía que los obreros lo tuvieran. Había un hombre que tenía reloj, pero se lo sacaron porque les decía la hora a los demás". (Ciencias Sociales)

\section{(6) InfoPlus \\ Fuga de cerebros}

Se conoce como "fuga de cerebros" al fenómeno de emigración de personas con formación profesional y altamente calificados hacia otros países que ofrecen buenas condiciones para el desarrollo profesional y mejores salarios.

Según un estudio de la Comisión Económica para América Latina y el Caribe (CEPAL), la Argentina fue el país de Latinoamérica que más científicos y técnicos aportó en la década de 1990 a los Estados Unidos. (Geografía)

(7) Hipócrates es considerado el padre de la Medicina, no tanto por los diagnósticos o tratamientos que pudo hacer, sino por la metodología que aplicó en sus investigaciones. Así explicaba en sus escritos:

"Cuando el sueño pone fin al delirio, ello es buena señal".

"Lasitud y cansancio sin causa es indicio de enfermedad".

"Las personas de edad pueden soportar el ayuno más fácilmente; después los adultos y los soporta menos la gente joven; y menos que nadie los niños y de estos aún los que no poseen una gran vitalidad".

Hipócrates (Biología)

Por un lado, en la casi totalidad de los casos analizados, los discursos referidos no introducen posturas contrapuestas o polémicas, sino que siguen la misma dirección argumentativa de la teoría. El autor utiliza el discurso ajeno para ampliar y enriquecer el 
saber expuesto y casi nunca para disentir o polemizar. Efectivamente, la referencia a otra voz se utiliza en general para expandir y ofrecer información sobre un aspecto apenas mencionado en la explicación. Por ejemplo, en (8) el fragmento del texto de Hobsbawm señala una cuestión relacionada con el tema de la teoría (la política de Stalin), pero que no ha sido desarrollada (la personalidad de Stalin) y sigue la misma línea argumentativa (la visión negativa sobre la política de Stalin). Por otro lado, el fragmento textual incorporado suele constituir un recurso didáctico que propicia una actividad, como el cuestionario que figura abajo.

\section{(8) C Stalin y la industrialización forzada}

Stalin, que presidió la edad de hierro de la URSS que vino a continuación [de la Nueva Política Económica], fue un autócrata de una ferocidad, una crueldad y una falta de escrúpulos excepcionales o, a decir de algunos, únicas. Pocos hombres han manipulado el terror en gran escala. No cabe duda de que, bajo el liderazgo de alguna otra figura del Partido Bolchevique, los sufrimientos del pueblo de la URSS habrían sido menores, al igual que la cantidad de víctimas. No obstante, cualquier política de modernización acelerada de la URSS, en las circunstancias de la época, habría resultado forzosamente despiadada, porque había que imponerla en contra de la mayoría de la población, a la que se condenaba a grandes sacrificios, impuestos en buena medida por la coacción. La economía de dirección centralizada responsable mediante los "planes" de llevar a cabo esta ofensiva industrializadora estaba más cerca de una operación militar que de una empresa económica.

Eric Hobsbawm, Historia del siglo XX, Barcelona, Crítica, 1995.

* Lean la lectura C. En ella, Hobsbawn hace una evaluación de las cualidades de Stalin como persona y como estadista. ¿Qué aspectos destaca? ¿Qué concesión hace a la política instrumentada por Stalin? ¿Cómo la justifica? (Ciencias Sociales)

De acuerdo con nuestro análisis, el tipo de cita que aparece en (8) es característico de los libros de texto de las décadas recientes y tiene propiedades y funciones particulares. Se trata de un tipo de cita que denominamos "cita marginal" y abordamos en el próximo apartado, donde, además, describimos ciertas operaciones discursivas llevadas a cabo con fines pedagógicos como la "fragmentación" y la “adaptación” de citas?.

\footnotetext{
${ }^{9}$ Respecto de la cantidad de citas en zonas paratextuales, la disciplina que mayor cantidad registra es Ciencias Sociales, luego le sigue Ciencias Naturales y finalmente Lengua y Literatura. Para consultar sobre un análisis comparativo entre disciplinas escolares, puede verse Tosi (2010b).
} 


\subsubsection{Las citas marginales: la voz ajena en la periferia}

Según ya se mencionó, las referencias a discursos aparecen en zonas paratextuales, como recuadros, plaquetas y otros recursos gráficos (por ejemplo, a través del diseño de un fichero, un volante, un afiche, una carta, una nota de diario de una época determinada, etc.). Entre las citas incorporadas, se destacan, en cuanto a cantidad e importancia, las que denominamos citas marginales.

Llamamos citas marginales a aquellas que se presentan separadas de la explicación y que no contribuyen necesariamente a la construcción colaborativa del conocimiento, en tanto no se utilizan para refutar, confrontar, tomarlas como aval o disentir de ellas. Si bien tienen ciertas similitudes con las citas destacadas, pues ambas presentan textos extensos (de más de tres o cuatro líneas) y aparecen en otro cuerpo y generalmente sin comillas, la diferencia reside en su relación con el texto citante. Mientras que las citas destacadas integran el texto citado y posibilitan la configuración conceptual (como en el caso 7), las citas marginales no influyen en el devenir discursivo de la exposición e, incluso, en muchos casos funcionan como discursos paralelos e independientes, como sucede en (8).

No obstante, y a diferencia de las citas destacadas de los géneros académicos, en las fuentes de las citas marginales suelen faltar algunos datos bibliográficos (como editorial, lugar y año de edición y página). Por ejemplo en (8), falta el número de la página de donde fue extraída la cita. Al respecto, afirmamos que los libros de textos no siempre cumplen con la rigurosidad en el citado completo que exige la tradición académica.

Las funciones principales de las citas marginales son, por un lado, ampliar un determinado aspecto del tópico a tratar a partir de la visión de un autor generalmente reconocido y legitimado en la comunidad académica disciplinar y, por otro, y generar una actividad, ya sea meramente contenidista, como ocurre en (8).

A su vez, distinguimos citas marginales integradas y citas no integradas. Hablamos de citas marginales integradas cuando en la explicación aparece una referencia que remite a la cita incluida, como sucede en (80, con la letra C, o en (10), con el símbolo \&. En el caso de las citas marginales no integradas, estas se colocan en forma independiente y emancipada del texto central, pues no se incluyen referencias ni remisiones. Aquí, el orden y la pertinencia de lectura de la cita queda a criterio del 
usuario del manual. Por ejemplo, en (9) se introduce una cita de Jorge Luis Borges, que ilustra las características del Ultraísmo, uno de los movimientos vanguardistas que es apenas mencionado en la teoría del capítulo en cuestión.

\section{(9) La estética del grupo Florida. Principios estéticos del ultraísmo}

1. Reducción de la lírica a su elemento primordial: la metáfora.

2. Tachadura de las frases medianeras, los nexos, y los adjetivos inútiles.

3. Abolición de los trabajos ornamentales, el confesionalismo, las circunstancias, las prédicas y la nebulosidad rebuscada.

4. Síntesis de dos o más imágenes en una, que ensancha de ese modo su facultad de sugerencia.

Borges, Jorge Luis. "Ultraísmo”, Nosotros 151, vol. 39, diciembre de 1921

(Lengua y Literatura)

Por otra parte, hay casos en los que la cita marginal se opone conceptualmente a la explicación central y plantea una controversia. Sin embargo, en la explicación misma no se explicita la polémica entre ambos textos; de esta forma, la cita funciona como un texto paralelo y la contradicción permanece tácita. Por ejemplo, en (10) el subtítulo "Consecuencias del descubrimiento de América" y la primera oración remiten a la cita marginal "Un juicio contemporáneo", donde Parry y Sherlock sostienen que es erróneo afirmar que Colón descubrió América. Es decir que la teoría usa el concepto "descubrimiento" sin conflictos e, incluso, lo expone como legítimo aunque sea refutado en el discurso citado.

(10) Consecuencias del descubrimiento de América

La expedición dirigida por Cristóbal Colón, en 1492, y los viajes que lo siguieron, pusieron en contacto dos mundos diferentes, y hasta entonces mutuamente desconocidos [\&10]

[\&10] Un juicio contemporáneo

Decir que Colón descubrió América es un error: Colón reveló a los europeos la existencia de continentes e islas que ya estaban habitados y los habían estado por muchos siglos. Colón no descubrió un nuevo mundo; tan solo estableció un contacto entre dos mundos, ambos ya viejos. Lo más importante es que lo hizo cuando los pueblos de Europa Occidental habían desarrollado barcos e instrumentos de navegación tan buenos como para mantener ese contacto por medio de viajes regulares, de manera que la gente, las plantas y los animales empezaron a fluir constantemente del mundo europeo al mundo americano. En la mayor parte de América latina, y aun en cierta medida en América del Norte, se produjo una unión más o menos estrecha de esos dos diferentes estilos de vida. En las Antillas, esa fusión resultó casi nula, pues el impacto que la Conquista provocó en la raza más débil fue muy poderoso.

Parry, J.H. y Sherlock, P. Historia de las Antilas. 
Actividad: 1. ¿Por qué objetan estos historiadores de nuestro tiempo el término "descubrimiento"? 2. ¿Qué factores dieron trascendencia a la empresa colombina? (Historia).

En este caso, la objeción que realiza la cita sobre el concepto de "descubrimiento" no es retomada por el texto citante que, por el contrario, lo presenta como válido. En efecto, en ningún momento se plantea la polémica entre la cita y explicación; en todo caso esta reflexión (delineada en una de las preguntas de la actividad) quedaría para el lector y la reflexión en el aula. Así, la cita constituye un texto paralelo y hasta autónomo conceptualmente del citante.

\subsubsection{Los discursos citados: fragmentación y adaptación}

Sin duda, la incorporación de una cita en cualquier género implica que el autor realice las operaciones de selección y fragmentación, entre otras. En efecto, el autor debe elegir qué fragmento textual colocará y si además cortará alguna parte. Diversas investigaciones han caracterizado la fragmentación discursiva en el libro de texto como excesiva, conflictiva y problemática (Carbone, 2003; Romero, 2004 y Somoza Rodríguez y Ossenbach Sauter, 2004). Por ejemplo, Romero se refiere a la fragmentación de la información como "abrumadora” y Somoza Rodríguez y Ossenbach Sauter (2004) sostienen que los libros escolares "proporcionan trozos más o menos parciales (y hasta inconexos), cada uno incompleto en sí mismo, y se espera que los alumnos los organicen en su mente y los reproduzcan como, ahora sí, un relato secuencial” (Somoza Rodríguez y Ossenbach Sauter, 2004: 5).

Según aconsejan diferentes manuales de estilo, si se omite una parte del texto que se transcribe, ya se trate de una única palabra o un fragmento, se señala con puntos suspensivo dentro de corchetes (García Negroni, 2010: 123) como observamos en (11), donde se reproducen algunos artículos fragmentados de la Constitución de la Ciudad Autónoma de Buenos Aires.

\section{(11) Documentos}

Constitución de la Ciudad Autónoma de Buenos Aires

Artículo 1. La Ciudad de Buenos Aires, conforme al principio federal establecido en la Constitución Nacional, organiza sus instituciones autónomas como democracia participativa y adopta para su gobierno la forma republicana y representativa [...] 
Artículo 2. La Ciudad de Buenos Aires se denomina de este modo o como "Ciudad Autónoma de Buenos Aires".

Artículo 3. Mientras la Ciudad de Buenos Aires sea Capital de la República, su Gobierno coopera con las autoridades federales que residen en su territorio para el pleno ejercicio de sus poderes y funciones. [...] (Ciencias Sociales)

Como sostiene Bernstein [1975] (2005), los principios internos del discurso pedagógico regulan la producción de objetos específicos e instaura reglas del orden discursivo que aluden a la selección y criterios del saber. Así, las citas suelen fragmentarse seguramente para que sean más acotadas o sencillas. Se sacan ciertas partes que se suponen más complicadas o que remiten, tal vez, a conceptos previos aparecidos en el texto citado.

Además de los efectos de sentido que genera la fragmentación y, que según los autores señalados atenta contra la comprensión global del texto, registramos una variación respecto del grado de fidelidad o veracidad de los textos incorporados. Si bien en muchas citas marginales figuran los datos bibliográficos correspondientes (como en 8 a 11), cuya función es, sin duda, avalar la originalidad del texto incluido, también hallamos otros en los que aparece la nominalización "adaptación" o el participio "adaptado", que aclaran que el texto ha sido transformado en alguna parte, aunque no se brinda datos de dónde y en qué medida (caso 12).

\section{(12) Nuevos agentes productivos en el agro pampeano}

A comienzos de la década de 1980 se produce un boom en la producción de cereales y oleaginosas. Este incremento deriva de la introducción de paquetes tecnológicos, la doble cosecha y la utilización de nuevas semillas.

El boom agrícola continúa hasta hoy y estimula el desarrollo de nuevos agentes, como los contratistas y los pools de siembra.

-Los contratistas son pequeños empresarios agrícolas sobremecanizados -cuentan con personal capacitado para el asesoramiento tecnológico, disponen de maquinarias y equipos, forman alianzas con fábricas de fertilizantes y semillas, etc.- que realizan tareas agrícolas en tierras arrendadas y reciben como pago por su trabajo parte de la cosecha.

-Los pools de siembra son empresas externas al sector agrícola -bancos, AFJP, inversionistas particulares- que se articulan mediante la conformación de un fondo común de inversión que destinan a la administración de explotaciones agropecuarias.

Norma Giarraca, "Procesos de globalización y cambios en la agricultura argentina", 1996 (adaptación). (Ciencias Sociales) 
Según hemos analizados en trabajos anteriores (Tosi, 2008), en los textos adaptados la voz ajena es modificada en pos de ciertos objetivos pedagógicos y/o comerciales. Por un lado, a través de la adaptación textual, se buscaría la adecuación del discurso al destinatario construido: se trata de textos de especialistas que suponen una cierta dificultad para el lector lego. Por otro lado, el fin comercial implica el ajuste a la política e ideología editorial, en tanto existen temas más polémicos o controvertidos que otros y que suponen una cierta cautela, como puede ser el tema del sida tratado en (13).

\section{(13) Identifican el gen del virus del sida que bloquea el sistema inmune}

(...)

Fuente: Adaptado de un artículo del diario "Clarín” del 27 de agosto de 2003. (Ciencias Naturales)

De esta manera, el autor del libro de texto, en contraposición con el autor académico, coloca su interés en construirse como accesible y comprensible, para poder guiar como mayor éxito al lector lego de acuerdo con las reglas de recontextualización del saber propias del género didáctico.

\section{Conclusiones}

En este trabajo presentamos un análisis acerca de ciertos aspectos microdiscursivos de los libros de texto de Secundario editados recientemente. Específicamente nos centramos en el abordaje de las formas de referencia a la voz ajena y, entre ellas, analizamos la inclusión de citas.

Por un lado, dimos cuenta de que en los segmentos explicativos de los libros escolares se evita introducir referencias explícitas a las voces disciplinares ajenas, con la pretensión de producir un discurso que se perciba objetivo y claro. Cuando los libros de texto introducen citas estas se ubican en forma separada y aislada de la voz impersonal construida en la explicación central. En efecto, las citas suelen exhibirse y mostrarse como un claro producto de un "otro" dentro de las zonas paratextuales. Por otro lado, caracterizamos las citas introducidas en el paratexto como recursos de expansión, pues suelen utilizarse para ampliar un tema a partir de una postura teórica generalmente afín a la expuesta en la teoría. A su vez, definimos y abordamos un tipo de cita característico de los libros de texto actuales. Se trata de las citas marginales, que son aquellas que no 
contribuyen necesariamente a la construcción colaborativa del conocimiento, en tanto no se utilizan para refutar, tomarlas como aval o disentir de ellas e, incluso, en muchos casos funcionan como discursos paralelos e independientes.

A partir del abordaje desarrollado, consideramos que la puesta en juego de estas estrategias microdiscursivas tiene como objetivo facilitar el abordaje de los estudiantes a los textos de estudio, pero que muchas veces no suele colaborar en el aprestamiento de textos especializados, los que se caracterizan por la presencia de diferentes voces y, por ende, por un alto nivel de argumentatividad.

Finalmente, esperamos que el presente trabajo contribuya a motivar en los docentes y profesionales de la edición una reflexión sobre el significado y alcance de los aspectos polifónico-argumentativos, como los aquí analizados, y que estos puedan ser tenidos en cuenta y considerados como elementos nodulares que inciden en el aprestamiento de la comprensión de textos especializados. En este sentido y tal como sostienen Marin y Hall: "Creemos que ayudar a los alumnos a comprender e interpretar no significa 'facilitar' los textos, sino enseñar a procesar los textos más difíciles, porque eso es democratizar el acceso al saber" (2003a: 5).

\section{Referencias bibliográficas}

Authier, J. (1984). Hétérogénéité(s) énonciative(s). Langages, 73, 98-111.

Authier, J. (1995). Ces mots qui ne vont pas de soi. Boucles réflexives et noncoïncidences du dire. Paris: Larousse

Bajtín, M. (1982). La estética de la creación verbal. México: Siglo XXI.

Bernstein, B. [1975] (2005) Clases, códigos y control II. Hacia una teoría de las transmisiones educativas. Madrid: Akal.

Bolívar, A. (2005). Tradiciones discursivas y construcción del conocimiento en las humanidades. Signo y Seña, 14, 67-91.

Carbone, G. (2003). Libros escolares. Una introducción a su análisis y evaluación. Buenos Aires: Fondo de Cultura Económica.

Chafe, W. (1986). Evidentiality in English conversation and academic writing. En E. W. Chafe \& J. Nichols (Eds.) Evidentiality: the Linguistic encoding of Epistemology (pp. 139-146.). New Jersey: Ablex.

Chevallard, Y. (1991). La transposición didáctica. Del saber sabio al saber enseñado. Buenos Aires: Aique.

Ducrot, O. [1984] (1986). El decir y lo dicho. Barcelona: Paidós.

García Negroni, M. M. (2008). Subjetividad y discurso científico-académico. Acerca de algunas manifestaciones de la subjetividad en el artículo de investigación en español. Revista Signos, 41(66), 5-31. 
García Negroni, M. M. (2010). Subjetividad, polifonía, y discurso académico en español. En Daher, M. (ed.) Escribir en español. Claves para una corrección de estilo. Buenos Aires: Santiago Arcos editor.

García Negroni, M.M., Hall, B. y Marin, M. (2005). El procesamiento de las nominalizaciones: un estudio polifónico-argumentativo”. En Panesi, J. y S. Santos (eds.) Actas del Congreso Internacional "Teorías críticas de la literatura y la lingüística". Buenos Aires: UBA.

García Negroni, M. M., Hall, B. y Marin, M. (2006). La argumentación y la polifonía implícita en la retórica académica. Actas del I Congreso de Lecturas Múltiples. Paraná: UNER. Versión electrónica: http://www.fcedu.uner.edu.ar/

Gülich, E. y Kotschi T. (1995), Discourse production in oral communication. En Quasthoff, U. (ed.) Aspects of oral communication. Berlín: Mouton de Gruyter.

Hyland, K. (2000). Disciplinary discourses. Social Internactions in academic writing. London: Longman.

Marin, M., Hall, B. (2003a). Los puntos críticos de incomprensión de lectura en los textos de estudio. Lectura y vida. Revista Latinoamericana de Lectura, 24 (1), 22-29.

Marin, M., Hall, B. (2003b). Marcas de argumentatividad en los textos de estudio: obstáculo para lectores. En Actas del Congreso Internacional "La argumentación: Lingüística, Retórica, Lógica, Pedagogía [CD Rom]. Buenos Aires: UBA,

Meinardi. E. (2005). Enseñanza de las Ciencias Naturales. Desafíos y propuestas. Publicación del Instituto Internacional de Planeamiento de la Educación y la Enseñanza de las Ciencias Naturales, 27.

Ministerio de Cultura y Educación de la Nación (1995). Contenidos Básicos Comunes para la Educación General Básica. Ministerio de Cultura y Educación de la Nación

Orlandi, E. (2009). A linguagem e seu funcionamento. As formas do discurso. Campinas: Pontes.

Pereira, C. y Di Stéfano M. (2001). Textos argumentativos y textos expositivos. En Panel temático del Segundo Simposio Internacional de Lectura y Vida. Buenos Aires, octubre.

Ramírez Gelbes, S. (2008). Discurso disciplinar, argumentación y ethos: qué recursos usan qué académicos. En Actas de III Simposio sobre análise do discurso: emoçoes, ethos e argumentaçao. Universidad Federal de Minas Gerais, Belo Horizonte, Brasil, 2008.

Romero, L. A. (coord.) (2004). La Argentina en la escuela. La idea de nación en los textos escolares. Buenos Aires: Siglo Veintiuno Editores.

Somoza Rodríguez M. y Ossenbach Sauter G. (2003). Los Manuales Escolares Españoles en la Época Digital. De la textualidad a la iconicidad. Universidad Nacional de Educación a Distancia. Disponible en http://hum.unne.edu.ar/investigacion/educa/web_relee/biblio.htm

Tosi, C. (2008). La voz ajena y la alteridad en los libros de texto. Un estudio polifónicoargumentativo en textos escolares argentinos. Matraga 22. Estudos Lingüísticos e Literários, 15(22), 114-128.

(2009). La construcción escenográfica del saber en los libros de texto. Páginas de guarda $7,32-51$. 
(2010a). La definición en los libros de texto. Acerca de como los comentarios metadiscursivos de denominación conforman el ethos disciplinar. Cuadernos del Sur - Letras, 38, 29-48.

(2010b). Discursive Traditions in the Pedagogic Discourse. A Comparative Analysis in Three Disciplines. Journal of Literature and Language, febrero, Baku, pp. 66-73.

(2010c). Escena genérica, escenografías y discurso ajeno en manuales escolares de Lengua y Literatura. Educación, Lenguaje y Sociedad 7. En prensa.

Zamudio, B. y Atorresi (2000). La explicación. Buenos Aires: Eudeba.

Corpus de análisis

Antokolec, P. et al. (2004). Ciencias Naturales 9. Buenos Aires: Editorial Puerto de Palos, 2006. Serie en estudio.

Arzeno, M. et al. (2005). Ciencias Sociales 9. Buenos Aires: Editorial Santillana. Serie Todos Protagonistas.

Ballanti, G. et al. (2005). Lengua 9. Buenos Aires: Editorial Santillana. Serie Todos Protagonistas.

Barderi, M., et al. (2005). Ciencias Naturales 9. Buenos Aires: Editorial Santillana. Serie Todos Protagonistas.

Berler, V. et al. (2004). Ciencias Naturales 9. Buenos Aires: Editorial Estrada. Serie Entender.

Bouzas, P. et al. (2006). Lengua y géneros discursivos 9. Buenos Aires: Editorial Puerto de Palos. Serie en estudio.

Díaz, S. et al. (2006). Geografía de la Argentina. Buenos Aires: Editorial Puerto de Palos. Serie en estudio.

Jáuregui, A. P. et al. (1988). Historia 2. Buenos Aires: Editorial Santillana.

Luchilo, L. et al. (2004). Ciencias Sociales 9. Buenos Aires: Editorial Estrada. Serie Entender.

Miretzky, M., Royo, S. y Salluzzi, E. (1992). Historia 2. La edad moderna y el surgimiento de la Nación Argentina. Buenos Aires: Editorial Kapelusz.

Pérez Aguilar, G., Muñoz, I. y Pérez de Lois, G. (1989). Lengua y Literatura 2. Buenos Aires: Santillana.

Petruzzi, H., Silvestri, M. y Ruiz, E. (1988). Lengua y Literatura III. Buenos Aires: Ediciones Colihue.

Romero, L. A. et al. (2006). Historia de los tiempos contemporáneos -Siglos XIX y XX. Buenos Aires: Editorial Puerto de Palos. Serie en estudio.

Vasallo. I. et al. (2004). Lengua 9. Buenos Aires: Editorial Estrada. Serie Entender.

Vattuone, L. (1986). Biología 1. Los organismos vivientes y su ambiente. Buenos Aires: Librería El Ateneo Editorial.

Zarur, P. (1985). Biología 2. Buenos Aires: Editorial Plus Ultra.

(Artículo recibido: 21-09-2010; revisado: 06-10-2010; aceptado: 15-10-2010) 